\title{
Psychosocial Family Post-landslide Disasters in the Mountain Areas: A Qualitative Study during COVID-19 Pandemic
}

\author{
Titin Sutini $^{1,2 *}$, Suryani Suryani ${ }^{2}$, Yanny Trisyani ${ }^{3}$ \\ ${ }^{1}$ Doctoral Study Program, Faculty of Medicine, Universitas Padjadjaran, Bandung, Indonesia; ${ }^{2}$ Department of Mental Health \\ Nursing, Faculty of Nursing, Universitas Padjadjaran, Bandung, Indonesia; ${ }^{3}$ Department of Critical Care and Emergency \\ Nursing, Faculty of Nursing, Universitas Padjadjaran, Bandung, Indonesia
}

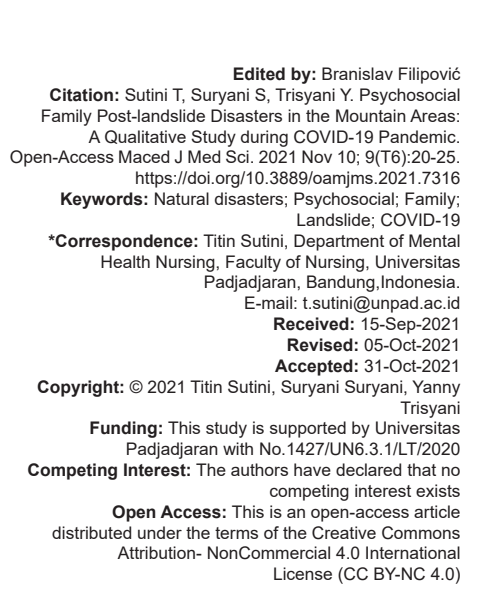

Abstract

BACKGROUND: Natural disasters and the COVID-19 pandemic can cause various physical, social, and psychological problems for families.

AIM: This study aims to determine the description of family psychosocial problems after the landslide disaster during the COVID-19 pandemic.

METHODS: A qualitative descriptive research approach is used to find out the description and problems in detail. Focus group discussions were conducted with eight respondents who were affected by landslides. Furthermore, data analysis was carried out descriptively by bringing up several themes.

RESULTS: We found four themes, namely, realizing there was something wrong with the physical, coping, and support system, sex being one of the primary needs, and the need to reduce psychosocial stress. From these fou themes, one theme was found, namely, sex being one of the primary needs needed by the participants. We also found that all respondents were not afraid of the COVID-19 condition, but instead, they were more worried about their next house and place to live. This triggers psychosocial problems in the families of disaster victims.

CONCLUSION: Family psychosocial problems experienced by landslide victims are eating and drinking, and psychosocial issues are also felt. The cause turns out to be from the effects of loss or the environment. Therefore nurses can carry out trauma healing interventions by considering the source of the problem from the family.

\section{Introduction}

Natural disasters can cause various problems in families both in the short and long term. Problems that arise are disturbances in psychological function, emotional adaptation, health, and children's development [1]. Psychological problems caused by social problems are referred to as psychosocial problems [2]. Psychosocial problems consist of a combination of three aspects, namely, biological, social, and psychological [3]. Psychosocial problems are a risk factor for disrupting a person's environmental health, which will impact his social health [4]. In the postlandslide situation, the triggering factor for the problem is the loss of property and family members so that psychologically there are problems, coupled with social conditions that require adapting in refugee camps so that ultimately it impacts his physical health.

A family is a person or more people who live together with legal and emotional attachments, where each individual has their role as part of the family [5]. The role and function of the family when a problem occurs, for example, a landslide, will experience changes, which can be a stress in itself for the family.

After the disaster, stress or family psychosocial problems can be of various kinds, including PTSD; 18 months after the earthquake, $55.2 \%$ of women and $33.4 \%$ of men experienced PTSD [6], shock, anxiety, and stress symptoms [7] changing roles in the family. There have been many post-disaster handling, especially for fulfilling physical needs such as food, psychological treatment, and trauma healing. However, psychosocial problems are still found because the problem's input continuously varies depending on the predictor factors that influence it.

In this study, the researcher aims to explore more deeply the psychosocial conditions experienced by refugees, especially refugee families affected by landslides in mountainous areas.

\section{Methods \\ Design}

The research design used is descriptive qualitative, which is used to describe or describe a problem, event, fact systematically, and accurately [8]. 


\section{Participants and settings}

Respondents in this study were eight people. The focus group discussions (FGDs) were used to dig up information about psychosocial problems faced by families after the landslide in evacuation sites during the COVID-19 pandemic. Respondents in this study were families affected by landslides in refugee camps. The sampling technique used is a non-probability sample by purposive sampling [9], with the inclusion criteria of the family (mother or father) who was affected by landslides and was in refugee camps, did not experience cognitive impairment, was physically healthy, could communicate well, and be cooperative. The place of research was carried out in the landslide evacuation tent Comanaging, Sumedang, Indonesia. Before the FGD, respondents were given informed consent about the activities to be carried out and explained the objectives, benefits for respondents, and gifts for the research process. This research has received ethical approval from the Ethics Committee of the Faculty of Medicine, Padjadjaran University, with ethics number 604/UN6.KEP/EC/202.

\section{Data collections}

Data collection was carried out on January 27, 2021. Data collection was carried out several times to obtain varied and extensive data. Data collection was assisted with a recording device and carried out directly by implementing safety according to COVID-19 standards, which was carried out at a distance and in an open area by wearing a mask. Data collection techniques were carried out by FGD. This technique was used to explore respondents' facts, problems, or experiences to produce data, where respondents were made in small groups [10], [11]. After giving informed consent about the research, a meeting schedule was made with all participants to discuss the psychosocial experiences they experienced while in refugee camps.

The FGD was conducted for $1.5 \mathrm{~h}$, and all participants could express their experiences and opinions well. However, some respondents require repetition of questions from the moderator. The guidelines for conducting FGDs are as follows: (1) Introduce yourself, explain the topic, the purpose of the activity, the time of the activity, and the rules during the activity. (2) Allow respondents to introduce themselves. (3) Open with open questions. "I am sorry to hear about the disaster that hit ladies and gentlemen. Are you all in good health?" (4) The question guide includes, "Can anyone share the feelings that you and your mother feel now after the landslide, especially now during the COVID-19 pandemic?" "Does these feelings interfere with your daily activities? What did your mother or father do to overcome it?" "What is the role of the family in dealing with this problem?" "How do you and your mother respond to this disaster?", "Did anyone experience physical pain because of thinking about this problem?" "What do you need the most now?" "Is there anything else you want to share in this forum?" and "all that we have discussed together, what is the most urgent thing that is needed now?" In the last FGD session, the moderator summarized the discussion results to validate them for the participants.

\section{Analisa data}

Data collection and analysis are an iterative process that coincides during research [10]. The data analysis model used is the Miles and Huberman (1984) model, where data analysis activities are carried out in four stages, namely, data collection, data reduction, data display, and conclusion/verification [8], [12]. Furthermore, the data from the FGD results were reduced by reading it repeatedly, summarizing, selecting the main things, looking for the important ones, and looking for patterns of themes. After that, the data are presented using narrative text and followed by a conclusion to find the latest things from the research results [13].

\section{Trustworthiness}

Trustworthiness in this research consists of credibility, transferability, dependability, and confirmability [14]. Credibility in this research is demonstrated by internal consistency, ensuring thoroughness throughout the research process, and always communicating the actions taken. Credibility is also supported by always concluding at the end of the FGD activities, to clarify the data received by the researchers. Record all data collection processes, both time, data results, FGD guides, and research aspects. Before conducting FGDs, there is always a briefing between the facilitator and the observers. Dependability consists of evidence and the accuracy of the data, seen from the results of the FGD recordings with the narration made. Conducting discussions in determining the research theme and verbatim result from the data, discussions were carried out with the research team. Transferability and confirmability are carried out between researchers and the team involved in the data collection process.

\section{Results}

Table 1 shows the characteristics of respondents who were conducted FGDs. Of the eight respondents, two were male as the head of the family, five were all female as wives, and in P8, a 69-year-old woman lived with her children and grandchildren, but this P8 acted as the head of the family. All respondents are victims of landslides in various locations of their houses. The worst position of the house is in P3, P4, and P8, where the house is no longer habitable because a landslide destroyed it. For homeownership for respondents P1-P6, the status of the house is already property, but 
for P7 and P8, it is still not absolute ownership because they are still paying the house installments.

Table 1: Participants characteristic

\begin{tabular}{lllll}
\hline Code & Occupation & Age & Gender & Family roles \\
\hline P1 & Housewife & 29 years & Female & Wife \\
P2 & Housewife & 34 years & Female & Wife \\
P3 & Private employee & 48 years & Male & Husband \\
P4 & Housewife & 43 years & Female & Wife \\
P5 & Private employee & 39 years & Male & Husband \\
P6 & Private employee & 31 years & Female & Wife \\
P7 & Housewife & 31 years & Female & Wife \\
P8 & Private employee & 69 years & Female & Husband \\
\hline
\end{tabular}

Four themes can be identified for psychosocial problems faced by families affected by landslides, namely, realizing something is wrong with their physical, coping, and support systems, sex being one of the primary needs, and the need to reduce psychosocial stress.

\section{Theme 1: Realizing there is something wrong with the physical}

This theme means that respondents realize that they are under stress, which impacts their physical appearance, but some respondents deliberately cover it up by pretending that there is no problem. The data show this:

"My blood pressure is going up, miss, this morning I just checked at the health post in front, and the result was high. They said 150/how much, I forgot again, even though l've never had high blood pressure before" (P3).

Other respondents also stated that they had physical complaints, such as the following respondents:

"I often have headaches, especially when I think about relocating because this house is still in installments and I don't know what to do next, so now I have to move, and how to calculate it later, I feel dizzy" (P7).

"Headaches, disturbed sleep, if there is a loud sound like waking up, still terrified of the landslide incident yesterday, because my house was swept away by the landslide and everything was finished, where is the house still in installments, I don't know what to do" (P8).

Some respondents stated that they were just sad and felt that they had no physical illness to complain about due to the sadness.

\section{Theme 2: Coping and support system}

Some respondents chose to surrender to this incident and prefer to leave everything to Allah, the almighty and omnipotent creator. This can be seen in the following respondent data:

"I just give up, hopefully, Allah will give you the best way, amen" (P2).

In line with the following respondents:
"I'm sad, I'm sorry, but what can I do? It's fate, so I finally just surrendered to all of Allah's provisions, I can only pray" (P6).

Some respondents feel that he will be fine and leave everything only to Allah. That is what the respondent stated above, as a way to calm his sad heart due to loss.

Support or support from friends or family is one of the drugs in dealing with various problems, including loss due to landslides. This can be seen in the following respondent data:

"Thank God I still have a wife who can pray for me to try to make a living and always encourage me, that Allah will surely make away, and our friends here also always strengthen each other so that we can continue to rise" (P3).

There are also other respondents, namely:

"My husband and I can only just give up, miss, hopefully, Allah will give us the best way, and it's true what the father said, our friends in this refugee tent also always comfort each other, so we don't get sad for a long time" (P6).

\section{Theme 3: Sex is a significant need}

Losing something can be objects or anything that can indeed have an impact on other needs. This can be called a coping response to balance the reaction to the perceived loss. Although, according to Maslow, there are five basic human needs. In addition to eating and drinking oxygen, other needs must be met even in a state of loss or stress, including sex. The respondent's data can be seen in the following respondents:

"Gathering like this can't do anything, miss, so privacy that is disturbed or not distributed, maybe miss, it's been three weeks and it keeps getting dizzier, huh... he... he..." (P1).

"There's a lot of food here, miss, but there's still something missing he... he... he..., and even if you're evacuated, that one lady has to be fulfilled, isn't it, miss, he...he...he. that's why it's too late for the luggage" (P3).

Support or support from friends or family is one of the drugs in dealing with various problems, including loss due to landslides. This can be seen in the following respondent data:

"Thank God I still have a wife who can pray for me to try to make a living and always encourage me, that Allah will surely take away, and our friends here also always strengthen each other so that we can continue to rise" (P3).

There are also other respondents, namely:

"My husband and I can only just give up, miss. Hopefully, Allah will give us the best way, and it's true what the father said, our friends in this refugee tent also 
always comfort each other, so we don't get sad for a long time" (P6).

\section{Theme 4: The need to reduce psychosocial} stress

All respondents are in refugee camps. They have been in evacuation for more than 2 weeks. According to all respondents, food, bathing, and health have been fulfilled. According to all respondents, the needs they need now vary, it can be seen in the following data:

"Home, the old life, no more headaches and high blood pressure" (P3).

While other respondents:

"House, miss, it's the same as privacy. How can you mix this? You can't do anything. That's why you're dizzy" (P1).

For P7 and P8, it is slightly different because the two respondents do not own their houses yet they are still paying in installments, so their needs are somewhat different, namely:

"Clarity about my destroyed house and how the mortgage is?" (P7 and P8).

All respondents had problems with their homes and wanted to return home, and not a single respondent was worried about the COVID-19 pandemic condition. When the landslide occurred, the number of COVID-19 cases increased. They think more about their worries about their home and their future survival, they do not think about whether they are afraid of contracting COVID-19. None of the respondents expressed their fear of catching COVID-19.

\section{Discussion}

\section{Theme 1: Realizing there is something wrong with the physical}

Stress is a stage that is manifested by a specific syndrome, where the syndrome will have an impact on biological systems non-specifically depending on the individual according to Selye (1976) [15]. Selye stated that a person's response to experiencing psychological problems begins with an alarm stage [15], [16], where individuals feel physical symptoms from their bodies, although each individual is different in responding to and realizing the problem, some are aware that their physical complaints are caused by previous stress, and some are not aware that this is the impact of psychosocial problems.

Some physical diseases can indeed be caused by stress, such as hypertension, which can be reduced by stress management interventions [17]. Another physical reaction is a headache due to the constriction of blood vessels to the brain. Each individual will have a different way of responding to stress. It cannot be equated. It depends on the various factors that influence it. However, Selye said that if the individual realizes that the physical disorder in his body is one of the impacts of psychosocial problems, then the healing process will be faster because the individual has positive insight to ask for help appropriately and quickly.

\section{Theme 2: Coping and support system}

Positive coping, positive support system, and perception of positive problems are three balancing factors in humans to avoid crises [18], especially post-traumatic crises such as PTSD. Natural disaster conditions affected the various physical, psychological, and social problems. In this study, respondents who were victims of landslides experienced various psychosocial issues, with various complaints, ranging from high blood pressure, dizziness, headaches, and decreased activity. Respondents in this study still have coping that is classified as still adaptive for now: Surrendering and surrendering to Allah and always praying. Maybe some have maladaptive coping where high blood pressure arises, which previously had never suffered by the respondent.

The results of the above explanation turned out to be for social support, or all respondents still own the support system, their perception of the problem is also positive and negative, and the coping used is still maladaptive, but is still in a reasonable stage as an alarm system in the body. It was explained above that humans have three balancing factors, where if two factors are still positive, then the individual will avoid a prolonged post-traumatic crisis [18], From the results of this study, the average respondent still has two positive things to balance to avoid a crisis.

\section{Theme 3: Sex is a major need}

Shelters make disaster victims adapt to the surrounding environment. This adaptation process can cause stress, tension, and even anxiety. The study results found that some respondents stated that their privacy was disturbed, and their sexual needs were disturbed, even though, according to some respondents, it might be one of the factors that could reduce stress or tension.

The study results did mention that sexual activity can have a relaxing effect and reduce anxiety in individuals who do it. This is due to the release of several relaxant hormones in the body [19]. However, the opposite can happen due to stress can also reduce a person's sexual activity or desire [19]. Therefore, seeing from the explanation above, it means that when providing disaster evacuation facilities, we must also 
pay attention to other biological needs, one of which is sex.

\section{Theme 4: The need to reduce psychosocial} stress

Respondents stated several needs, but the most basic requirement for respondents was for all to answer the house because the needs for food, drink, and oxygen were felt to be sufficient. However, the health needs, especially fear of contracting COVID-19, were not felt by the respondents. According to the respondent, psychosocial stress is a problem, but the possible solution is still in fulfilling the house.

The causes of stress are multifactorial. Therefore, knowing the source of stress will facilitate the intervention process or handling of refugees. The first step in implementing is to first understand the cause or predictor factor [18]. By knowing the predictor factors, the implementation will be right on target. Stuart's stress adaptation approach model also said that starting from looking for predisposing factors, precipitation, perception of stressors, individual coping, and support systems, then the book of Isa determines the intervention [20].

\section{Conclusion}

The psychosocial problems of families who experienced landslides were stressful and psychosomatic. The victims of the landslides felt other issues. Psychosocial problems arise from their social environment and based on the family's perception of the problem, coping, needs, and social support. This study also explored other problems that might be able to alleviate psychosocial problems experienced by families, namely, sexual needs.

The findings of this study have three implications for community-based mental health services. First, human needs, according to the hierarchy, are not only fulfilled for food, drink, and oxygen but other requirements must also be fulfilled, which are the basis, this privacy which is challenging to give must be fulfilled. Second, for nurses and professionals, post-disaster trauma healing has indeed been carried out, but it should be explored first what is the source of stress in the victim. Third, the government should provide accurate information for disaster victims to reduce the stress suffered by the victims.

\section{References}

1. Couch SR, Coles CJ. Community stress, psychosocial hazards, and EPA decision-making in communities impacted by chronic technological disasters. Am J Public Health. 2011;101 Suppl 1:S140-8. https://doi.org/10.2105/ ajph.2010.300039

PMid:21836109

2. Sarafino EP, Smith TW. Health psychology: Biopsychosocia interactions. United States: John Wiley and Sons; 2014.

3. Newman BM, Newman PR. Development Through Life: A Psychosocial Approach. United States: Cengage Learning; 2017.

4. Miller JL. Psychosocial Capacity Building in Response to Disasters. New York, United States: Columbia University Press; 2012.

5. Friedman MM, Bowden VR. Buku Ajar Keperawatan Keluarga. Tamil Nadu:EGC; 2010

6. Naeem F, Ayub M, Masood K, Gul H, Khalid M, Farrukh A, et al. Prevalence and psychosocial risk factors of PTSD: 18 Months after Kashmir earthquake in Pakistan. J Affect Disord. 2011;130(1):268-74. https://doi.org/10.1016/j.jad.2010.10.035

7. Reifels L, Pietrantoni L, Prati G, Kim Y, Kilpatrick DG, Dyb G, et al. Lessons learned about psychosocial responses to disaster and mass trauma: An international perspective. Eur $\mathrm{J}$ Psychotraumatol. 2013;4(1):22897. https://doi.org/10.3402/ejpt. v4i0.22897

PMid:24371515

8. Sugiyono PD. Metode Penelitian Kuantitatif Kualitatif and RND Bandung, Alfabeta CV. Tegallega: Skripsi Fakultas Ekonomi Universitas Widyatama; 2010

9. Braun V, Clarke V. Successful Qualitative Research: A Practica Guide for Beginners. New York, United States: SAGE; 2013.

10. Tenny S, Brannan GD, Brannan JM, Sharts-Hopko NC Qualitative Study. Treasure Island, FL: Stat Pearls; 2021.

11. Scheelbeek PF, Hamza YA, Schellenberg J, Hill Z. Improving the use of focus group discussions in low income settings. BMC Med Res Methodol. 2020;20(1):287. https://doi.org/10.1186/ s12874-020-01168-8 PMid:33256625

12. Sudibyo P. Perbedaan penelitian kualitatif dan kuantitatif. In: Seminar Kelas Mata Kuliah Metodologi Penelitian Pendidikan Islam Universitas Sunan Kalijaga (Hal. 1-9). Vol. 23. Yogyakarta: UIN Sunan Kalijaga; 2016. p. 2020. https://doi.org/10.31943/ jurnal_risalah.v6i1.123

13. Miles MB, Huberman AM, Saldana J. Qualitative Data Analysis: A Methods Sourcebook. New York, United States: SAGE; 2014.

14. Lincoln YS, Guba EG. Trustworthiness and Naturalistic Evaluation, Program No. 30; 1986.

15. Rice VH. Handbook of Stress, Coping, and Health: Implications for Nursing Research, Theory, and Practice. Vol. 38. New York, United States: SAGE. 2001

16. Emaliyawati E, Ibrahim K, Trisyani $\mathrm{Y}$, Mirwanti R, Ilhami FM, Arifin $H$. Determinants of nurse preparedness in disaster management: A cross-sectional study among the community health nurses in coastal areas. Open Access Emerg Med. 2021;13:373-9. https://doi.org/10.2147/oaem.s323168 PMid:34385845

17. Sutini T, Emaliyawati E. Pemberdayaan masyarakat tentang cara perawatan hipertensi dengan menggunakan manajemen stress di desa ciganjeng dan karangsari kecamatan padaherang kabupaten pangandaran. J Keperawatan Sriwij. 2018;5(1):19-23. 
18. Halter MJ, Pollard CL, Jakubec SL. Varcarolis's Canadian Psychiatric Mental Health Nursing, Canadian Edition-E-Book. Amsterdam, Netherlands: Elsevier Health Sciences; 2018.

19. Gold PW. The organization of the stress system and its dysregulation in depressive illness. Mol Psychiatry.
2015;20(1):32-47.

PMid:25486982

20. Stuart GW. Principles and Practice of Psychiatric Nursing-E-Book. Amsterdam, Netherlands: Elsevier Health Sciences; 2014. 